\title{
Development of an Aerosol Dose Collection Apparatus for In Vitro Dissolution Measurements of Orally Inhaled Drug Products
}

\author{
Robert Price, ${ }^{1,6}$ Jagdeep Shur, ${ }^{1}$ William Ganley, ${ }^{1}$ Gonçalo Farias, ${ }^{1}$ Nikoletta Fotaki, ${ }^{1}$ Denise S. Conti, ${ }^{2}$ \\ Renishkumar Delvadia, ${ }^{2,3}$ Mohammad Absar, ${ }^{2,4}$ Bhawana Saluja, ${ }^{2,4}$ and Sau Lee ${ }^{5}$
}

Received 15 August 2019; accepted 10 January 2020; published online 13 February 2020

\begin{abstract}
The aim of the study was to develop a robust and standardized in vitro dissolution methodology for orally inhaled drug products (OIDPs). An aerosol dose collection (ADC) system was designed to uniformly deposit the whole impactor stage mass (ISM) over a large filter area for dissolution testing. All dissolution tests were performed under sink conditions in a sodium phosphate buffered saline solution containing $0.2 \% \mathrm{w} / \mathrm{w}$ sodium dodecyl sulphate. An adapted USP Apparatus V, Paddle over Disk (POD), was used throughout the study. The dissolution characteristics of the ISM dose of a commercial metered-dose inhaler (MDI) and a range of dry powder inhaler (DPI) formulations containing inhaled corticosteroids were tested. The uniform distribution of the validated ISM dose considerably reduced drug loading effects on the dissolution profiles for both MDI and DPI formulations. The improvement in the robustness and discriminatory capability of the technique enabled characterization of dissolution rate differences between inhaler platforms and between different DPI product strengths containing fluticasone propionate. A good correlation between in vivo mean absorption time and in vitro dissolution half-life was found for a range of the inhaled corticosteroids. The ADC system and the reproducible in vitro POD dissolution measurements provided a quantitative-based approach for measuring the relationship between the influence of device and the dispersion characteristics on the aerosol dissolution of low solubility compounds. The in vitro dissolution method could potentially be applied as a dissolution methodology for compendial, quality control release testing, and during development of both branded orally inhaled drug products and their generic counterparts.
\end{abstract}

KEY WORDS: aerosol; inhaled corticosteroids; dissolution; bioequivalence.

Electronic supplementary material The online version of this article (https://doi.org/10.1208/s12248-020-0422-y) contains supplementary material, which is available to authorized users.

\footnotetext{
${ }^{1}$ Pharmaceutical Surface Science Research Group, Department of Pharmacy \& Pharmacology, University of Bath, Bath, BA2 7AY, UK.

${ }^{2}$ Office of Research and Standards, Office of Generic Drugs, Center for Drug Evaluation and Research, Food and Drug Administration, Silver Spring, Maryland, USA.

${ }^{3}$ Present Address: Office of New Drug Products, Office of Pharmaceutical Quality, Center for Drug Evaluation and Research, Food and Drug Administration, Silver Spring, Maryland, USA.

${ }^{4}$ Present Address: Office of Clinical Pharmacology, Office of Translational Sciences, Center for Drug Evaluation and Research, Food and Drug Administration, Silver Spring, Maryland, USA.

${ }^{5}$ Office of Testing and Research, Office of Pharmaceutical Quality, Center for Drug Evaluation and Research, Food and Drug Administration, Silver Spring, Maryland, USA.

${ }^{6}$ To whom correspondence should be addressed. (e-mail: r.price@bath.ac.uk)
}

\section{INTRODUCTION}

For a locally acting inhaled drug product to elicit a pharmacological effect, the therapeutic dose must first reach the mucosal surface, lining the respiratory tract. Upon reaching the respiratory mucosa, the fate of the inhaled drug substance is not well understood. However, it is believed that the critical determinants that affect the local drug concentration at the sites of action, as well as the rate and extent of drug absorption through the lung, are the deposition pattern (i.e., the distribution of the respirable dose among mouththroat regions, conducting and peripheral airways), the molecular properties of the active pharmaceutical ingredient (API) and the need for the drug to be in solution, that is, the in vivo dissolution kinetics (1).

Currently, since local drug concentrations throughout the respiratory tract cannot be measured in a practical way, determining local equivalence between test and reference products in developing bioequivalent generic products is very challenging and more complicated than for systemically 
acting drugs. Furthermore, with the limited understanding of the relationship among conventional in vitro performance parameters [e.g., aerodynamic particle size distribution (APSD) profiles, mass median aerodynamic diameter (MMAD), fine particle dose (FPD), and delivered dose] and the dissolution and absorption kinetics of the respirable dose, the development of bioequivalent orally inhaled drug products (OIDPs) is extremely challenging. The US Food and Drug Administration (FDA) currently recommend the aggregated weight of evidence approach to establish bioequivalence between test and reference OIDPs (2). This relies on comparative in vitro studies (for equivalence in product performance) and comparative in vivo studies [pharmacokinetic $(\mathrm{PK})$ for equivalence in systemic exposure and pharmacodynamic (PD) or clinical endpoint (CE) for equivalence in drug delivery at the sites of action] in addition to formulation sameness (Q1 and Q2, i.e., the same inactive ingredients and at the same concentration $\pm 5 \%$ as the reference product) and device similarity. This weight of evidence approach has been used by FDA to draft individual product-specific guidance to assist in the development programs of generic OIDPs.

In the case of generic OIDPs, the identification, validation, and standardization of novel in vitro and in silico tools may provide an insight into the relationship between regional drug deposition and the extent and rate of drug exposure at the local sites of action in the lungs. This may ultimately provide an alternative regulatory pathway for demonstrating bioequivalence of generic OIDPs without the need to conduct in vivo comparative $\mathrm{PD}$ or CE studies.

For poorly soluble drugs, the correlation between aqueous solubility and mean absorption time (MAT) for a range of compounds in the lungs suggests that dissolution may be the rate limiting step for absorption (3). Furthermore, dissolution of the respirable dose in the limited fluid lining the central airways is in kinetic competition with the pulmonary mucociliary clearance mechanism (4). Thus, the bioavailability of the pulmonary deposited dose, both locally and systemically, may be directly affected by the dissolution characteristics in the air-liquid interface. In silico mechanistic modeling of the systemic exposure of a poorly soluble drug substance, with different aerodynamic particle size distributions, highlighted that the slight difference in deposition pattern could not explain the observed differences in plasma profiles and indicated that the rate of dissolution was the rate limiting step of absorption into the systemic circulation (5).

The major challenges in developing an in vitro dissolution test for OIDPs have been reviewed by both the USP $A d$ Hoc Inhalation Advisory Panel in 2008 and the dissolution working group of the IPAC-RS in $2012(6,7)$. They reviewed all published methodologies for aerosol collection and dissolution testing of OIDPs, available at those times. The major findings of both groups were that all methodologies lacked the robustness and the level of validation required for a standardized dissolution test, either as a quality control tool to assess batch consistency or in establishing a quantitative in vitro-in vivo relationship between dissolution data and systemic PK profiles.

The major challenge in the development of a dissolution approach for OIDPs remains the aerosol collection system and the associated apparatus for measuring dissolution of a representative pulmonary dose. May et al. (2012) investigated the influence of different dose collection methods, membrane holders, and dissolution media on the dissolution process (8). The authors highlighted the critical need to collect a homogenous distribution of the aerosolized dose onto a membrane to increase the discriminatory capability of the dissolution measurements. Indeed, one of the drawbacks of commercially available aerosol filter-based collection systems is that the dissolution rate is highly sensitive to the collected dose and decreases with increasing collected mass of a given formulated product (8). The effect is thought to be due to the formation of in situ agglomerates, created by the impactor jets, during collection onto the filter membrane surface. This results in agglomerates of drug particles that cannot be fully wetted by the dissolution media. Thus, these collection systems can lead to a significant increase in the probability of particle-particle aggregation, which directly influences the sensitivity and discriminatory capability of dissolution rate measurements.

The goal of this study was to develop a bespoke aerosol dose collection (ADC) system together with an adapted USP Apparatus V, Paddle over Disk (POD) (9), which may constitute a significant step toward providing reliable dissolution data to gain a better understanding of the potential relationships among OIDP formulations and local and systemic bioavailability. The major specific, technical objective of the study was to validate the impactor stage mass (ISM) dose collected by the ADC, with respect to the ISM dose collected by the Next Generation Impactor (NGI), and to significantly improve the robustness and discriminatory capability of the in vitro dissolution test through uniform distribution of the aerosolized dose across a high surface area filter. All dissolution tests were undertaken with a selection of commercially available OIDPs containing glucocorticoids, which, with their poor water solubility and negligible oral bioavailability, were selected as suitable candidates for investigation.

\section{MATERIALS AND METHODS}

\section{Materials}

Commercial 50, 125, and $250 \mu \mathrm{g}$ fluticasone propionate (FP) MDIs \{Flixotide ${ }^{\circledR}$ Evohaler $\AA$ \}; 100, 250, and $500 \mu \mathrm{g}$ FP DPIs \{Flixotide $®$ Accuhaler $®$ \}; 50/100, 50/250, and 50/500 $\mu \mathrm{g}$ salmeterol/fluticasone propionate combination (S/FP) DPIs \{Seretide $\AA$ Accuhaler ${ }^{\circledR}$ \}; and 200/25 $\mu \mathrm{g}$ fluticasone furoate/ vilanterol combination (FF/V) DPIs \{Relvar ${ }^{\circledR}$ Ellipta $\left.®\right\}$ were purchased from GlaxoSmithKline. Commercial $220 \mu \mathrm{g}$ mometasone furoate (MF) DPIs \{Asmanex ${ }^{\circledR}$ Twisthaler ${ }^{\circledR}$ \} were purchased from Merck. All products were tested well before their expiry date.

Reference standards (1 g) of FP, FF, and MF were purchased from LGC Standards (Middlesex, UK). Sodium phosphate buffered saline (PBS) solutions \{prepared using sodium phosphate monobasic dihydrate $\left(\mathrm{NaH}_{2} \mathrm{PO}_{4} \cdot 2 \mathrm{H}_{2} 0\right.$, $\mathrm{MW}=156.01 \mathrm{~g} / \mathrm{L})$, sodium phosphate dibasic $\left(\mathrm{Na}_{2} \mathrm{HPO}_{4}\right.$, $\mathrm{MW}=141.96 \mathrm{~g} / \mathrm{L}), 0.1 \mathrm{M}$ hydrochloric acid $(\mathrm{HCl})$, and sodium chloride $(\mathrm{NaCl}, \mathrm{MW}=58.44 \mathrm{~g} / \mathrm{L})\}$ were purchased from Fischer Scientific (Loughborough, UK). Pall A/E type glass fibre filters (47 mm diameter, $1 \mu \mathrm{m}$ nominal pore size) were purchased from Copley Scientific (Nottingham, UK). 
Whatman Puradisc ${ }^{\mathrm{TM}}$ polytetrafluoroethylene (PTFE) filters (13 $\mathrm{mm}$ diameter, $0.2 \mu \mathrm{m}$ pore size) were purchased from Scientific Laboratory Supplies (Nottingham, UK). Water used during the studies was Milli-Q Reverse Osmosis purified (Merck Millipore, Darmstadt, Germany). Sodium dodecyl sulphate (SDS) and polyoxyethylene (80) sorbitan monooleate (Tween 80), and methanol and acetonitrile were of high performance liquid chromatography (HPLC) grade and purchased from Sigma (Gillingham, UK). Adirondack Alcohol Ink (Raisin TIM22145) was purchased from Tim Holtz® (Ranger Ink, NJ, USA).

\section{Solubility Measurements}

Saturated solutions of FP were prepared by adding an excess of the drug into a PBS solution at $\mathrm{pH}=7.4$ containing $0.2 \% \mathrm{w} / v$ SDS. Solutions were held at $37^{\circ} \mathrm{C}$ for $24 \mathrm{~h}$ prior to filtration. All solubility measurements were performed in triplicate.

\section{Scanning Electron Microscopy (SEM)}

Drug filters were sputter coated with gold (Edwards Sputter Coater S150B, Edwards High Vacuum, Sussex, UK) to achieve a thickness of approximately $20 \mathrm{~nm}$. All SEM imaging was performed using a scanning electron microscope (JEOL JSM6480LV, Tokyo, Japan) using $15 \mathrm{kV}$ accelerating voltage. The magnification was set to $\times 1000$.

\section{Dissolution Studies}

All dissolution studies were conducted in an adapted USP Apparatus V, also known as Paddle over Disk (POD), traditionally used for transdermal delivery systems (10). All dissolution measurements were performed at $37^{\circ} \mathrm{C}$ in a $300 \mathrm{~mL}$ PBS and $0.2 \% w / v$ SDS dissolution media with a stirring speed of $75 \mathrm{rpm}$. The USP disk assembly membrane holder for transdermal patches was adapted to enable a $47 \mathrm{~mm}$ glass fiber filter to be housed. A $50 \mathrm{~mm}$ diameter stainless steel disk assembly was used with a 74 mesh screen (NW-50-CR-SV-74, Nor-Cal Inc., USA). For all dissolution experiments, $3 \mathrm{~mL}$ aliquots were withdrawn at 2.5, 5, 10, 15, 20, 25, 30, 60, 120, 180, and $240 \mathrm{~min}$ time intervals and filtered with a $0.2 \mu \mathrm{m}$ PTFE syringe filter directly into HPLC vials. To maintain a constant volume in the dissolution vessel, the sampling volume was replaced with pre-warmed dissolution media. Each dissolution study was performed in triplicate. The total amount of drug loaded onto the filters were determined by the sum of the cumulative mass released together with any mass retained on the membrane after $4 \mathrm{~h}$. The fractional percentage of the drug dissolved at each time point was determined by dividing the amount of drug by the total mass loading.

\section{Kinetic Modeling of Drug Release and Dissolution Release Profile Comparison Testing}

The dissolution profiles of all commercial products were fitted to zero-order, first-order, Higuchi, Hixson-Crowell, and Korsmeyer and Peppas models to ascertain the most appropriate kinetic modeling of drug release. For all batches of commercial products, the most appropriate model was the first-order drug release.

Model-independent methods were also applied to compare the dissolution release profiles. The mean dissolution time (MDT) of the profiles was calculated by the following equation (11):

$$
M D T=\frac{\sum_{i=1}^{n} T_{i} \Delta M_{i}}{\sum_{i=1}^{n} \Delta M_{i}}
$$

Where $n$ is the number of dissolution sample time points, $i$ is the sample number, $\Delta \mathrm{Mi}$ is the fraction of drug release between $t_{\mathrm{i}}$ and $t_{(\mathrm{i}-1)}$, and $T_{\mathrm{i}}$ is the calculated midway time point between sampling, where $T_{\mathrm{i}}=\left(t_{\mathrm{i}}+t_{(\mathrm{i}-1)}\right) / 2$.

A similarity factor (f2) analysis was also calculated to compare dissolution release profiles of MDI and DPI products containing FP between the initial sampling time point and the cumulative mass at $120 \mathrm{~min}$. The $\mathrm{f} 2$ value was considered similar when not less than 50 , which is equivalent to an average difference of no more than $10 \%$. The similarity factor analysis has been adopted by the regulatory authorities as a criterion for the assessment of similarity between test and reference in vitro dissolution profiles (11).

\section{High Performance Liquid Chromatography (HPLC)}

Chemical analyses of active pharmaceutical ingredients were detected using an HPLC system which consisted of a binary pump coupled to an autosampler and a variable wavelength UV detector (Agilent 1200, Wokingham, UK) that was set to $235 \mathrm{~nm}$. The pump flow rate was set to $1.0 \mathrm{~mL} / \mathrm{min}$ through a Hypersil ODS $\mathrm{C}_{18}$ column (Fisher Scientific, Loughborough, UK, column length of $50 \mathrm{~mm}$, internal diameter of $4.6 \mathrm{~mm}$, and particle size of the packing material of $5 \mu \mathrm{m}$ ), which was placed in a column oven (Agilent, Wokingham, UK) set to $40^{\circ} \mathrm{C}$. The mobile phase consisted of methanol, acetonitrile, and water $(32.5,32.5,35 \% v / v)$. The experimental run time was $3.5 \mathrm{~min}$. For all HPLC studies, a linear regression analysis was used for the assessment of the HPLC calibration. Quantification was carried out by an external standard method, and linearity was verified between 0.05 and $50 \mu \mathrm{g} / \mathrm{mL}$.

\section{Design and Development of the Aerosol Dose Collection (ADC) System}

To overcome the apparent influence of the aerosol collection method on in vitro dissolution release profile, a bespoke aerosol dose collection (ADC) system was designed and built. Briefly, the main objectives were the following: (1) to collect and validate against a standard NGI the whole impactor stage mass (ISM) onto a high surface area filter, (2) to obtain dissolution release profiles independent of drug loading, and (3) to attempt to increase the overall ruggedness, reliability, and discriminatory capability of in vitro dissolution based measurements of OIDPs for quality control and bioequivalence testing.

A cross-sectional schematic of the ADC system that was incorporated within stage 2 of an NGI, in this particular study, is shown in Fig. 1. The impactor nozzle in the interstage plate of the NGI was removed and replaced with a tapered, circular orifice. The removal of the jets from the impactor nozzle led 


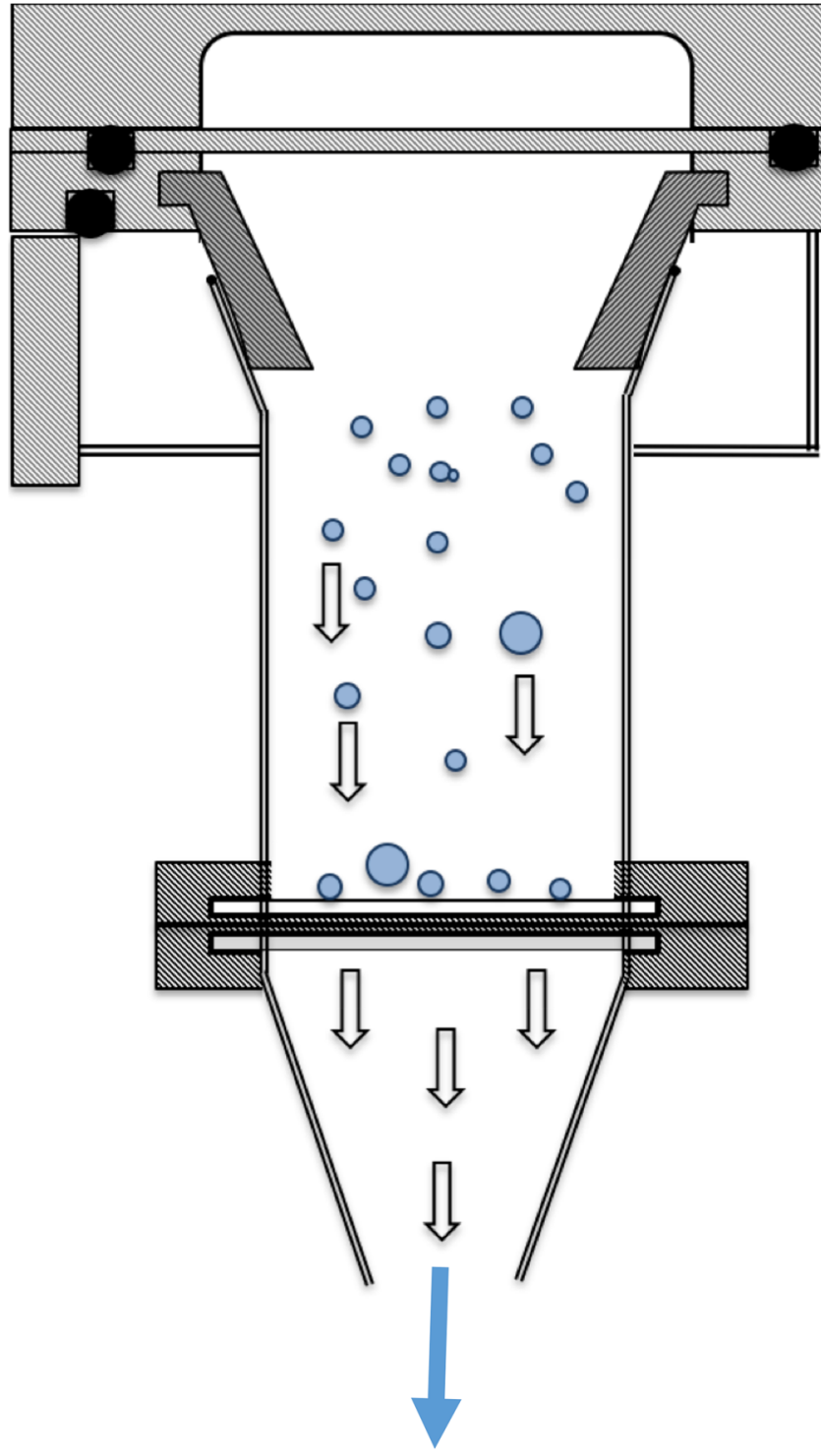

\section{Vacuum/Flow Controller}

Fig. 1. A schematic cross-sectional diagram of the aerosol dose collection (ADC) system, which was incorporated into stage 2 of the NGI

to a significant reduction in the exit air velocity, while laminar flow behaviour (i.e., Reynolds number $500<\mathrm{Re}<3000$ ) was maintained across the calibrated flow rates of the NGI (30$100 \mathrm{~L} / \mathrm{min}$ ). The difference in the air velocity exiting stage 2 was calculated to be an order of magnitude less with the use of a single, circular orifice (from $891 \mathrm{~cm} / \mathrm{s}$ with the jets to $83.7 \mathrm{~cm} / \mathrm{s}$ at $60 \mathrm{~L} / \mathrm{min}$ ). The combination of low air flow velocity and the distribution of the whole pneumatic air across a large diameter orifice were specifically designed to enable uniform deposition of the aerosol dose.

To harvest the aerosol dose, the collection system was directly mounted onto the tapered nozzle. The dose collection housed a removable holder for an appropriate $47 \mathrm{~mm}$ diameter filter that was arranged orthogonally to the direction of the pneumatic flow. The dose collector was connected directly to a vacuum pump via a flow controller (TPK Model, Copley Scientific, Nottingham, UK). This enabled the collection of all the dose below any remaining NGI stage and allowed a direct unimpeded pathway extending from the orifice to the filter.

\section{RESULTS AND DISCUSSION}

Upon initially validating the dose collection efficiency of the ADC system, the apparatus was used to investigate loaded dose effects (approximately 50-500 $\mu \mathrm{g}$ ) on the dissolution release profiles of both $250 \mu \mathrm{g}$ FP DPI and $125 \mu \mathrm{g}$ FP MDI. The system was also used to study the relationship between mean absorption time and dissolution kinetics of a series of low solubility inhaled corticosteroids. Finally, the dissolution characteristics of FP from the three different product strengths of FP MDI, FP DPI, and S/FP DPI products were compared.

\section{Validation of the Dose Collection Efficiency of the ADC System}

To validate the collection efficiency of the ADC system, the ISM collected onto the glass fiber filter within the ADC, from a commercial $250 \mu \mathrm{g}$ FP DPI, was compared with standard in vitro NGI recovery at a flow rate of $60 \mathrm{~L} / \mathrm{min}$. As shown in Fig. 2, with increasing number of actuations $(1,2,5$, and 10), there is good correlation between the ISM collected from the conventional NGI and the ADC system over the range of mass loadings studied.

The uniformity of deposition across a filter surface with the ADC system was visualized by formulating an alcoholic ink (Raisin (TIM22145), Tim Holtz ${ }^{\circledR}$ Adirondack Alcohol Inks, USA) as a $0.5 \% \mathrm{w} / v$ solution-based MDI. As shown in the photographic images in the supplementary information (Fig. S1), the uniformity and increasing intensity of the ink with increasing number of actuations suggested that the aerosol dose was being uniformly deposited across the whole collection filter surface.

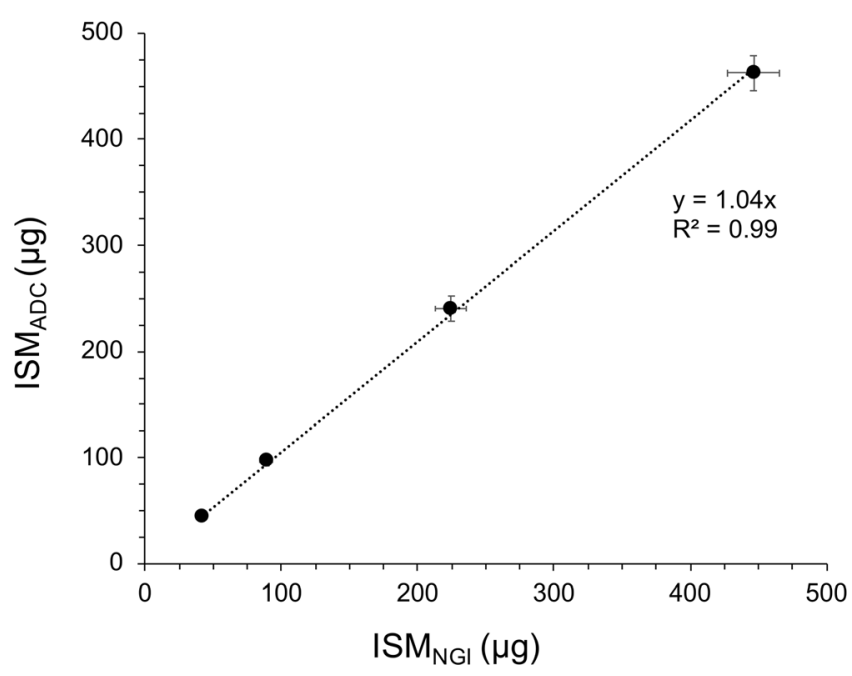

Fig. 2. Validation of the mean impactor stage mass (ISM) collection

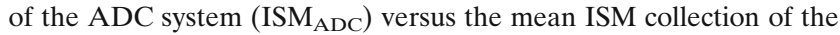
NGI $\left(\mathrm{ISM}_{\mathrm{NGI}}\right)$, for increasing number of actuations of the $250 \mu \mathrm{g} \mathrm{FP}$ DPI tested at $60 \mathrm{~L} / \min (\mathrm{n}=3$, mean $\pm \mathrm{SD})$ 
Representative scanning electron microscope (SEM) micrographs of the ISM collected dose with increasing number of actuations of the $250 \mu \mathrm{g}$ FP DPI tested at $60 \mathrm{~L} /$ min and $125 \mu \mathrm{g}$ FP MDI tested at $30 \mathrm{~L} / \mathrm{min}$ are shown in Figs. 3 and 4, respectively. As indicated by the SEM micrographs, the local deposition density of the FP particles, which increased from 2.6 to $26.6 \mu \mathrm{g} / \mathrm{cm}^{2}$ and from 3.9 to $38.3 \mu \mathrm{g} / \mathrm{cm}^{2}$ for 1 and 10 actuations of the $250 \mu \mathrm{g}$ FP DPI and $125 \mu \mathrm{g}$ FP MDI, respectively, led to minimal aggregation and in situ agglomeration formation.

\section{Solubility Determinations of FP for Dissolution Studies}

The solubility of fluticasone propionate (FP) at $37{ }^{\circ} \mathrm{C}$ in a $10 \mathrm{mM}$ sodium phosphate buffered saline solution $(\mathrm{pH}=7.4)$ with the addition of $0.2 \% \mathrm{w} / \mathrm{w}$ SDS was $14.2 \pm 3.4 \mu \mathrm{g} / \mathrm{mL}$. To ensure that sink conditions could be maintained over a wide range of FP drug loading, the concentration in the dissolution media should not exceed $10 \%$ of the saturated solubility in the respective media $(10,11)$. The total volume of dissolution media $(300 \mathrm{~mL})$ was selected to maintain sink conditions with increasing drug loading while maintaining sufficient sensitivity to detect any formulation differences.

\section{Dissolution Release Profiles as a Function of Loaded Dose}

Drug coated filters from the ADC system were carefully loaded and secured onto a stainless steel disk assembly for Paddle over Disk (POD) for dissolution measurements. The dissolution release profiles, plotted as cumulative mass percentage $(\%)$ of the total dose recovered after $4 \mathrm{~h}$, of FP with increasing number of actuations $(1,2,5$, and 10) from a commercial $250 \mu \mathrm{g}$ FP DPI and a $125 \mu \mathrm{g}$ FP MDI, are shown in Fig. 5a and b, respectively. These plots suggest that the dissolution release profiles of FP were independent of drug loading (approximately 50-500 $\mu \mathrm{g}$ ) even though the surface coverage of FP on the filters varied, on average, between 2.6 and $38.3 \mu \mathrm{g} / \mathrm{cm}^{2}$. These findings are supported by similarity factor (f2) analysis of the dissolution profiles. The $\mathrm{f} 2$ values between all the different numbers of actuations were between $84-85$ and 8688 for the DPI and MDI dissolution profiles, respectively.

In comparing the dissolution release profiles from the $250 \mu \mathrm{g}$ FP DPI and $125 \mu \mathrm{g}$ FP MDI products, the dissolution rate of the ISM dose of FP appeared to be significantly faster from the DPI than the MDI. These observations were supported by the $\mathrm{f} 2$ analysis $(\mathrm{f} 2=35)$, mean dissolution time (MDT), and first order release modeling results of the profiles, which are summarized together with the data from other product strength in Table I. While these findings could be related to differences in the upper aerodynamic cut-off diameters of the collected ISM dose for the MDI $(\leq 11.7 \mu \mathrm{m})$ and the DPI $(\leq 8.1 \mu \mathrm{m})$, there appears a link with observed in vivo differences in the mean absorption time of FP from MDI and DPI products (12). Thorsson et al. (2001) indicated that the rate of absorption of FP upon inhalation in healthy patients was slower from the MDI than the DPI (13). These findings are further supported by recent animal testing by Kuehl et al. who indicated a marked decrease in the systemic absorption rates of FP from a commercial MDI product with respect to dry powder formulation preparations (14).

The increase in dissolution rate of FP from an interactive mixture is supported by a large body of evidence in solid dosage
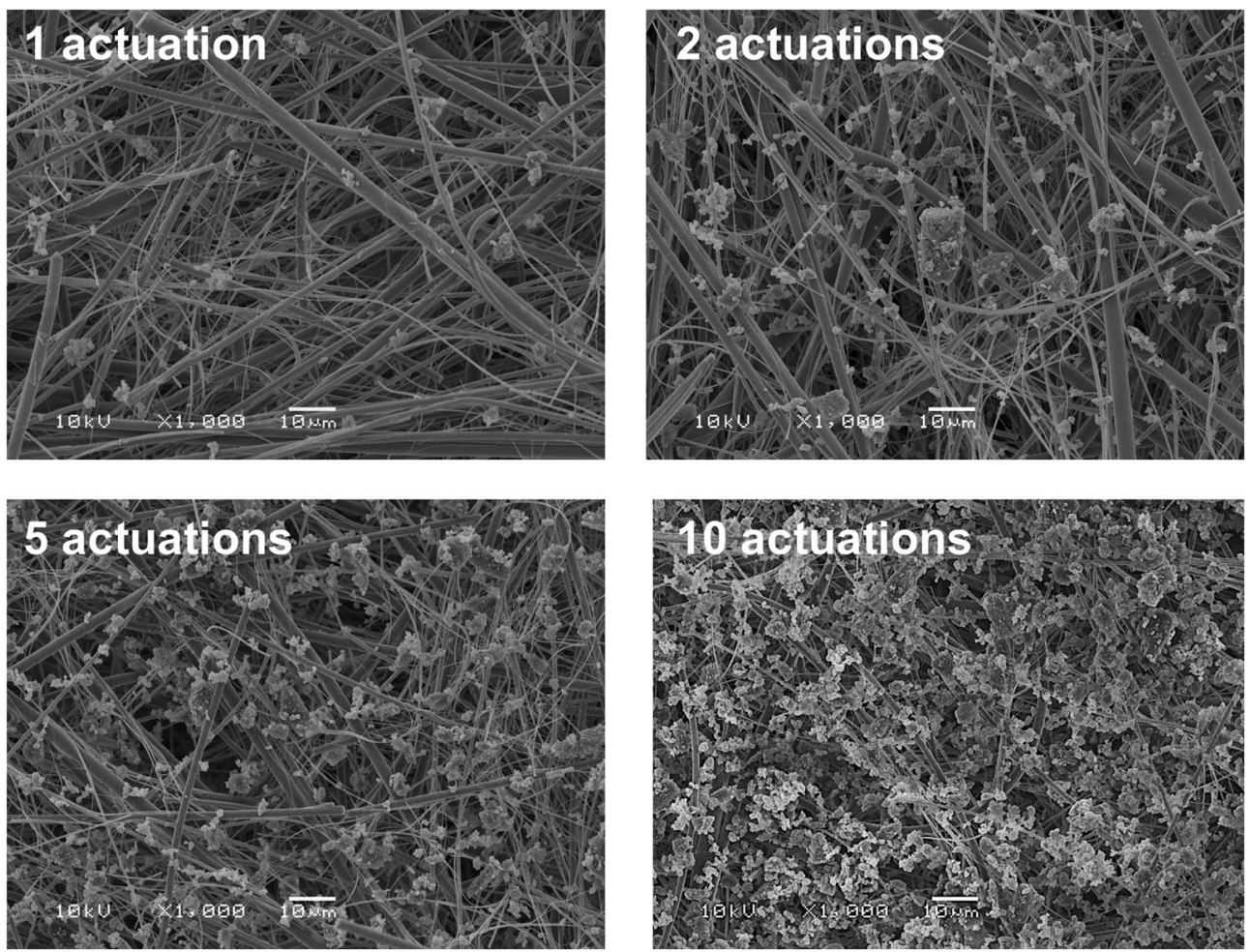

Fig. 3. Representative scanning electron microscope (SEM) micrographs of the ISM dose collected using the ADC system for an increasing number of actuations of the $250 \mu \mathrm{g}$ FP DPI at a flow rate of $60 \mathrm{~L} / \mathrm{min}$. Magnification $\times 1000$ for all SEM micrographs shown 

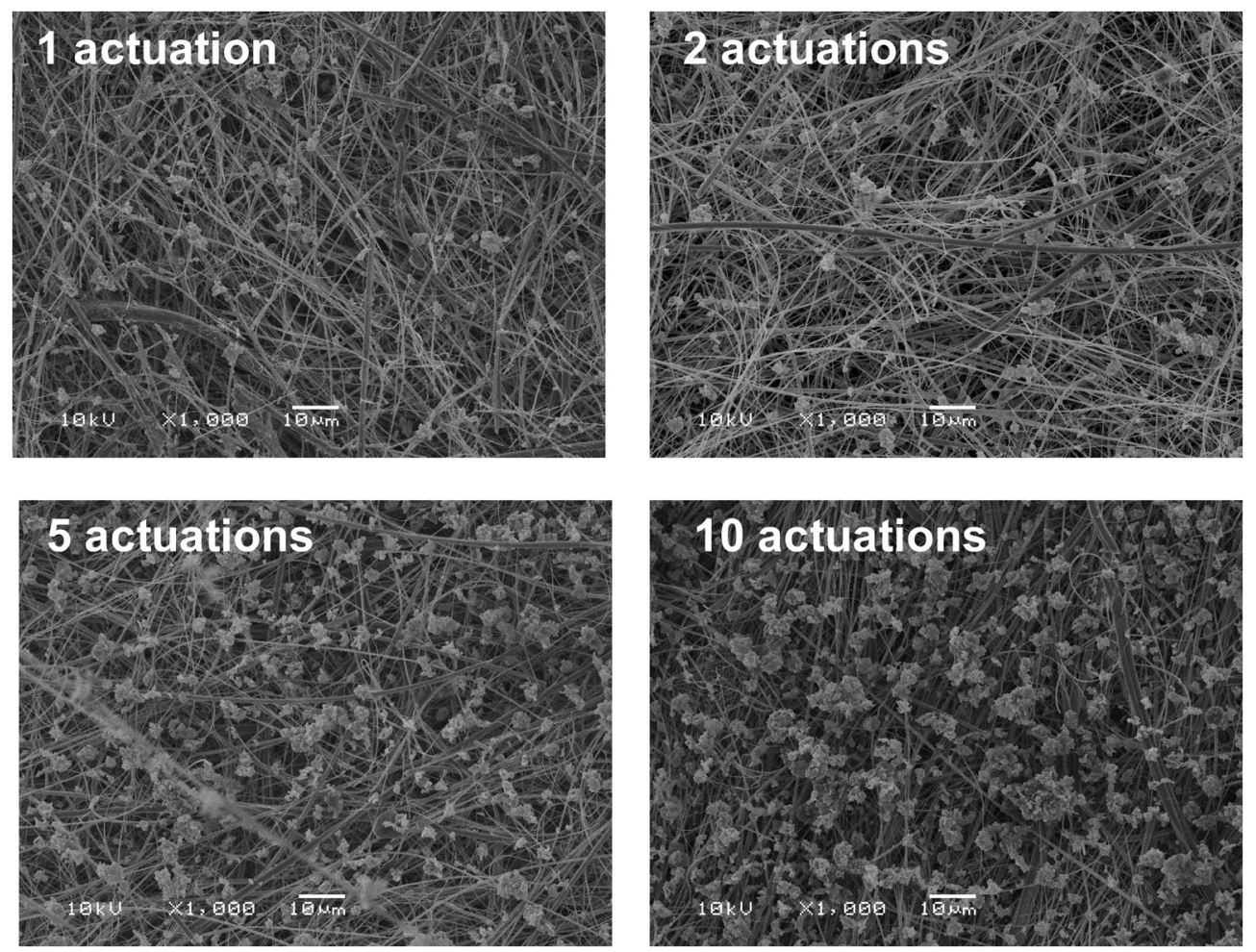

Fig. 4. Representative scanning electron microscope (SEM) micrographs of the ISM dose collected using the ADC system for an increasing number of actuations of the $125 \mu \mathrm{g}$ FP MDI at a flow rate of $30 \mathrm{~L} / \mathrm{min}$. Magnification $\times 1000$ for all SEM micrographs shown

forms literature (12,15-17). A significant increase in dissolution rate of low solubility, micronized drugs can be achieved when formulated as an interactive mixture with a soluble excipient $(12,15-17)$. These studies indicate that the deagglomeration and distribution of discrete fine particles over the surface of a soluble carrier particle can lead to dissolution rates that are even higher than that of a well dispersed suspension of a micronized drug. The pre-requisite for these high rates of dissolution is directly related to the instantaneous dissolution of the fine carrier particles (15). It could be argued that the aerosolization and dispersion of the drug from a coarse carrier may lead to fully deaggregated drug particles. However, as indicated by the SEM micrograph in the supplementary information (Fig. S2), a proportion of the collected FP remains dispersed over the surface of fine lactose particles. The rapid dissolution of these fine excipient particles within the lining fluid of the lungs may therefore lead to a significant increase in the surface area of the FP particles available to be wetted by the dissolution media. Furthermore, studies have shown that the addition of fine lactose as a ternary additive with a coarse lactose carrier can lead to a further increase in the dissolution rate of drugs when formulated as a low-dose interactive mixture for oral drug delivery $(18,19)$.

\section{Relationship Between Dissolution Rate Measurements and In Vivo Mean Absorption Time}

Mechanistic-based predictions of drug absorption and plasma concentration profiles of low solubility, lipophilic inhaled corticosteroids have suggested that deposition patterns and pulmonary dissolution is the rate-limiting step for local and systemic absorption of these permeable drugs $(5,7)$. In these models, the rate of dissolution is simulated based on solubility measurements and regional deposition patterns from particle size distribution measurements. While these simulated dissolution rates have been shown to correlate well with PK-based measurements of mean absorption time (MAT), attempts to confirm this relationship using in vitro-based dissolution measurements have generally failed.

To support these in silico models, the aerosol dissolution of a range of ICS MDI and DPI drug products was compared to the mean absorption time (MAT) of PK measurements from elsewhere $(13,20,21)$. A plot of the literature values of MAT versus dissolution half-life (experimental data from this study) is shown in Fig. 6. These data and the dissolution kinetics are summarized in Table II. In vitro dissolution data from this study correlated well with MAT measurements, in the sense that the rate of pulmonary absorption of low soluble, highly permeable ICS molecules is limited by dissolution. Solubility measurements are rather limited as they do not consider physicochemical differences in relation to particle size, surface area, and the actual process of dispersion and deaggregation of the API via an inhaler device. These effects are highlighted by the differences in the FP DPI and MDI formulations, where only dissolution related studies can characterize the direct impact of formulation/device dependency on the dissolution behavior of these compounds.

\section{Influence of Product Strength on In Vitro Dissolution of FP}

To investigate the possible influence of different product strengths on the aerosol dissolution properties of micronized fluticasone propionate, dissolution release 

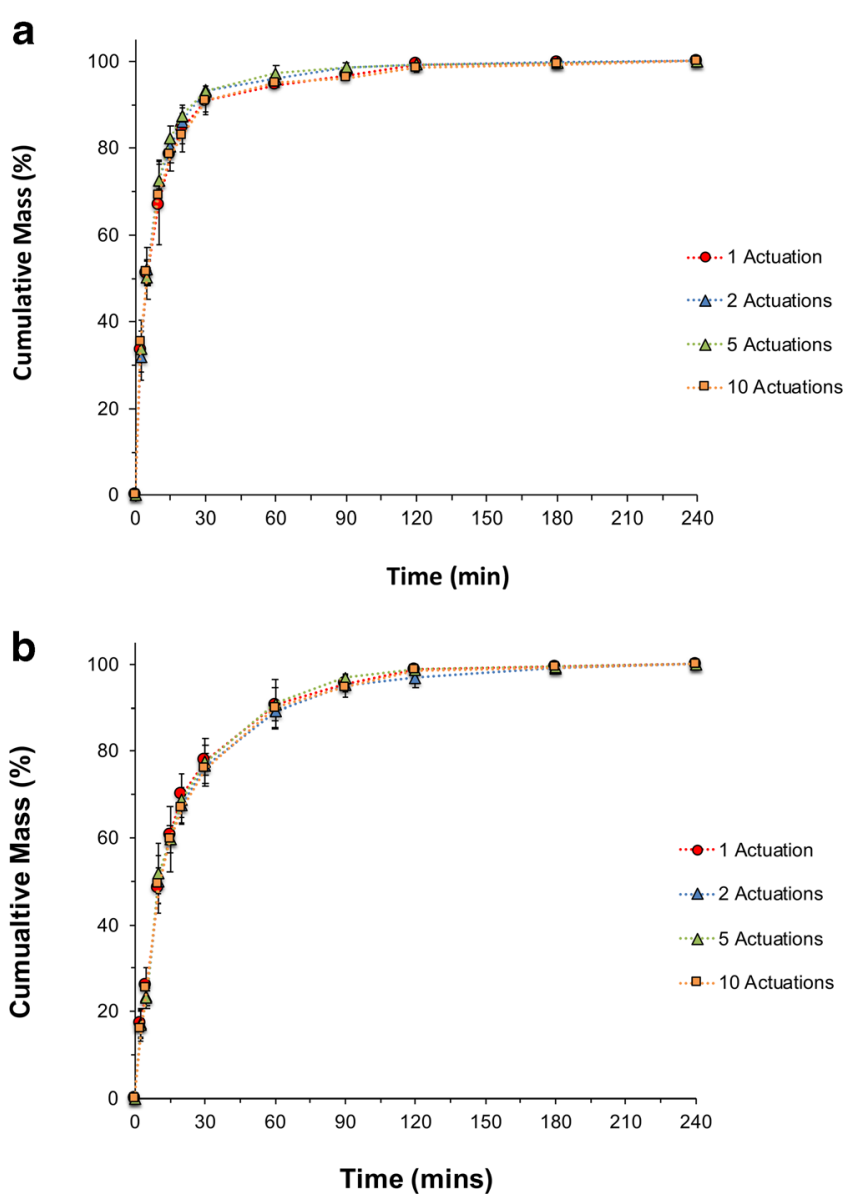

Fig. 5. Cumulative mass (\%) dissolution profiles of the FP ISM dose with increasing number of actuations of a $250 \mu \mathrm{g}$ FP DPI collected using the ADC system at $60 \mathrm{~L} / \mathrm{min}$, and $\mathbf{b} 125 \mu \mathrm{g}$ FP MDI collected using the $\mathrm{ADC}$ system at $30 \mathrm{~L} / \mathrm{min}(\mathrm{n}=3$, mean $\pm \mathrm{SD})$.

profiles of commercial 50, 125, and $250 \mu \mathrm{g}$ FP MDIs, 100, 250, and $500 \mu \mathrm{g}$ FP DPIs, and 50/100, 50/250, 50/500 $\mu \mathrm{g} \mathrm{S/}$ FP DPIs were measured. The dissolution profiles of the ISM dose collected from the three product strengths of FP MDI are shown in Fig. 7. The dissolution kinetics and percentage concentration of FP $(\% w / w)$ within the MDI products are summarized in Table I. The profiles indicate

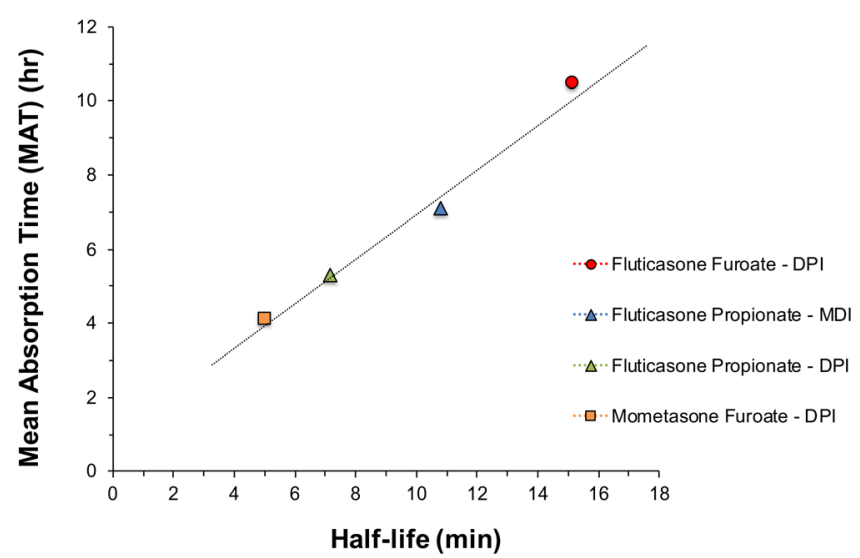

Fig. 6. Plot of the mean absorption time (MAT) (17) versus the first order dissolution half-life $(\mathrm{n}=3)$ (experimental data from this work) for a series of inhaled corticosteroids

that the dissolution kinetics of FP was independent of the percentage concentration of the drug within the MDI formulation.

The dissolution profiles, for an equivalent nominallabeled dose (equivalent to a $500 \mu \mathrm{g}$ label claim dose), of the FP DPI and S/FP DPI products formulated at three different strengths are shown in Fig. 8a and b, respectively. The dissolution kinetics of the different product strengths are summarized in Table I.

For a fixed concentration of salmeterol (S) and a constant carrier fill weight $(12.5 \mathrm{mg})$, increasing the surface coverage of FP led to a concomitant decrease in rate of dissolution in both mono- and dual-therapy combination products (22). Similarity factor (f2) analysis suggested that none of the product strengths, for both FP DPI and S/FP DPI, had a similar dissolution profile. The decrease in rate of dissolution with increasing drug concentration is supported by previous studies that have shown that the dissolution rate of a poorly soluble compound in an interactive mixture is inversely proportional to the degree of surface coverage and more specifically to the surface area ratios between drug and carrier $(15,18)$. These studies suggested that with increasing drug loading, there is a greater likelihood of drug-

Table I. Drug loading and dissolution kinetics of the FP ISM dose $(n=3$, mean \pm SD) for different portable inhaler devices and their different product strengths.

\begin{tabular}{|c|c|c|c|c|c|c|}
\hline Product & $\begin{array}{l}\text { Labeled Dose } \\
(\mu \mathrm{g})\end{array}$ & FP Loading $(\% w / w)$ & $\begin{array}{l}\text { ISM } \\
(\mu \mathrm{g})\end{array}$ & $\begin{array}{l}\mathrm{k}_{1} \\
\left(\min ^{-1}\right)\end{array}$ & $\begin{array}{l}\mathrm{T}_{0.5} \\
(\mathrm{~min})\end{array}$ & $\begin{array}{l}\text { MDT } \\
(\min )\end{array}$ \\
\hline \multirow[t]{3}{*}{ FP MDI } & 50 & 0.08 & $75.2 \pm 5.9$ & $0.060 \pm 0.003$ & $11.64 \pm 1.10$ & $20.80 \pm 1.64$ \\
\hline & 125 & 0.13 & $118.0 \pm 6.4$ & $0.064 \pm 0.003$ & $10.78 \pm 0.84$ & $19.41 \pm 1.02$ \\
\hline & 250 & 0.32 & $99.2 \pm 8.5$ & $0.061 \pm 0.003$ & $11.45 \pm 0.60$ & $19.40 \pm 0.58$ \\
\hline \multirow[t]{3}{*}{ FP DPI } & 100 & 0.79 & $109 \pm 4.9$ & $0.110 \pm 0.001$ & $6.32 \pm 0.12$ & $8.83 \pm 0.60$ \\
\hline & 250 & 1.96 & $97.4 \pm 7.2$ & $0.097 \pm 0.003$ & $7.15 \pm 0.28$ & $9.85 \pm 0.83$ \\
\hline & 500 & 3.85 & $97.2 \pm 8.6$ & $0.092 \pm 0.006$ & $8.13 \pm 0.42$ & $11.07 \pm 0.91$ \\
\hline \multirow{3}{*}{ S/FP DPI } & $50 / 100$ & 0.79 & $110.3 \pm 2.9$ & $0.138 \pm 0.03$ & $5.03 \pm 0.17$ & $6.30 \pm 0.49$ \\
\hline & $50 / 250$ & 1.95 & $108.6 \pm 1.9$ & $0.112 \pm 0.006$ & $6.18 \pm 0.43$ & $9.87 \pm 0.80$ \\
\hline & $50 / 500$ & 3.83 & $109.4 \pm 4.8$ & $0.106 \pm 0.008$ & $7.35 \pm 0.61$ & $10.49 \pm 1.03$ \\
\hline
\end{tabular}

$k_{1}$ First order rate constant, $T_{0.5}$ The mean dissolution half-life of the drug release, $M D T$ Model independent mean dissolution time 
Table II. Mean absorption time (MAT) [16] and dissolution kinetics (calculated using the experimental data from this work, $\mathrm{n}=3$, mean \pm SD) of low aqueous solubility inhaled corticosteroids.

\begin{tabular}{llllll}
\hline Product & $\begin{array}{l}\text { Labeled Dose } \\
(\mu \mathrm{g})\end{array}$ & $\begin{array}{l}\text { MAT } \\
(\mathrm{h})\end{array}$ & $\begin{array}{l}\mathrm{k} 1 \\
(\mathrm{~min}-1)\end{array}$ & $\begin{array}{l}\text { T0.5 } \\
(\mathrm{min})\end{array}$ \\
\hline FF/V DPI & $200 / 25$ & 10.5 & $0.046 \pm 0.002$ & $15.14 \pm 0.98$ & $\begin{array}{l}\text { MDT } \\
(\mathrm{min})\end{array}$ \\
FP MDI & 125 & 7.1 & $0.064 \pm 0.003$ & $10.78 \pm 0.84$ & $23.81 \pm 2.86$ \\
FP DPI & 250 & 5.3 & $0.097 \pm 0.003$ & $7.15 \pm 0.28$ & $9.85 \pm 0.83$ \\
MF DPI & 220 & 4.1 & $0.138 \pm 0.021$ & $4.99 \pm 0.74$ \\
\hline
\end{tabular}

drug agglomerate formation over discrete drug particlecarrier interactions.

Interestingly, the presence of a fixed dose of $50 \mu \mathrm{g}$ micronized salmeterol (S) within the carrier blends led to an increase in the rate of dissolution of the FP in the $\mathrm{S}$ / FP DPI products. These observations are supported by $\mathrm{f} 2$ similarity factor analysis, which indicated that the dissolution profiles of FP from the collected ISM dose of the 100, 250, and $500 \mu \mathrm{g}$ FP DPIs were dissimilar to the respective concentrations of FP in the S/FP DPI products. The increase in the rate of dissolution of FP within the dual-therapy combination products may suggest that more soluble salmeterol could play a supporting role in facilitating the increase in area of exposure of the FP, particularly due to the high solubility of the salmeterol and lactose within the dissolution media.

\section{CONCLUSIONS}

In this study, we have designed and engineered a novel dose collection system for in vitro dissolution testing of orally inhaled drug products that uniformly distributed the whole impactor stage mass (ISM) onto a single membrane surface. The validated dose collection method was utilized to demonstrate that dissolution profiles of both commercial MDI and DPI products were independent of loaded dose over a wide range of concentrations

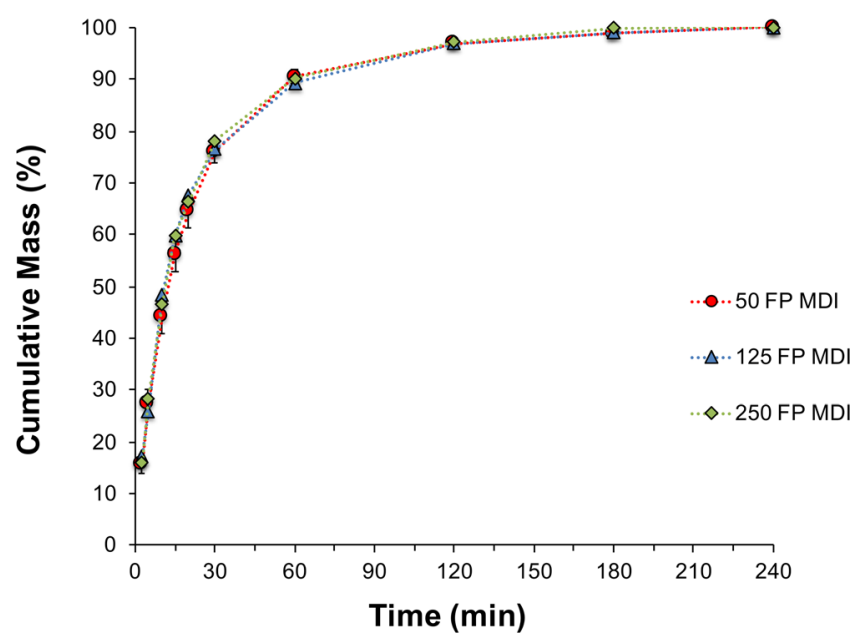

Fig. 7. Cumulative mass \% dissolution profiles of FP for 1 actuation of the $250 \mu \mathrm{g}, 2$ actuations of the $125 \mu \mathrm{g}$ and 5 actuations of the $50 \mu \mathrm{g}$ FP MDI collected at a flow rate of $30 \mathrm{~L} / \mathrm{min}(\mathrm{n}=3$, mean \pm SD) of drug loading. The independence of the dissolution rate measurements with loaded mass allowed quantitative comparisons to be made between formulation characteristics and dissolution behavior. The increase in robustness and the discriminatory capability of the dissolution method developed in this work may enable quantitativebased comparisons of orally inhaled drug products (interand intra-batches) and may aid in the development of a standardized dissolution method for compendial testing of orally inhaled drug products.
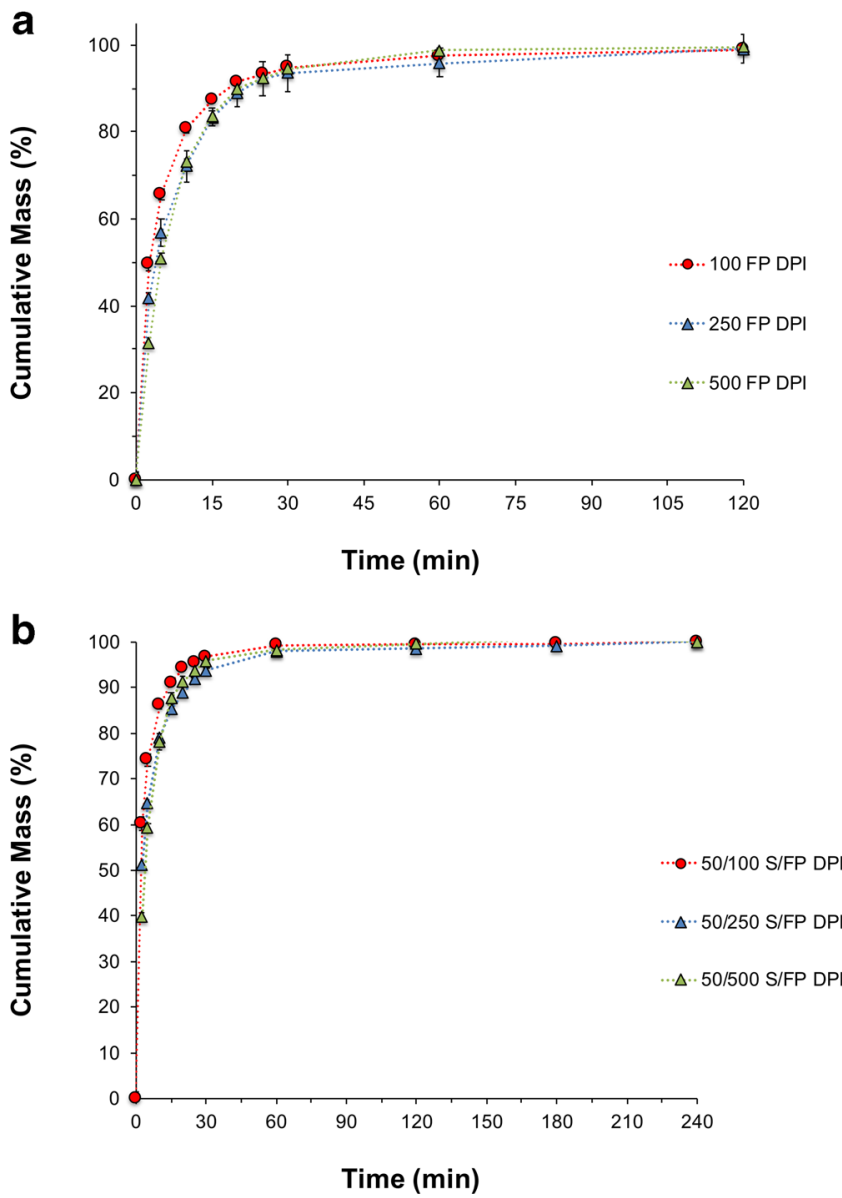

Fig. 8. a Cumulative mass $\%$ dissolution profiles of FP for an equivalent label claim dose of the 100, 250, and $500 \mu \mathrm{g}$ FP DPIs b Cumulative mass \% dissolution profiles of FP for an equivalent label claim dose of the 50/100, 50/250, and 50/50 $\mu \mathrm{g} \mathrm{S/FP} \mathrm{DPIs.} \mathrm{Flow} \mathrm{rate}$ was set to $60 \mathrm{~L} / \min (\mathrm{n}=3$, mean \pm SD) 


\section{FUNDING INFORMATION}

Funding for this work was made possible, in part, by the US Food and Drug Administration through grant 1U01FD004953.

\section{COMPLIANCE WITH ETHICAL STANDARDS}

Conflict of Interest Views expressed in this article are from the authors and do not necessarily reflect the official policies of the Department of Health and Human Services, nor does any mention of trade names, commercial practices, or organization imply endorsement by the US Government.

Open Access This article is licensed under a Creative Commons Attribution 4.0 International License, which permits use, sharing, adaptation, distribution and reproduction in any medium or format, as long as you give appropriate credit to the original author(s) and the source, provide a link to the Creative Commons licence, and indicate if changes were made. The images or other third party material in this article are included in the article's Creative Commons licence, unless indicated otherwise in a credit line to the material. If material is not included in the article's Creative Commons licence and your intended use is not permitted by statutory regulation or exceeds the permitted use, you will need to obtain permission directly from the copyright holder. To view a copy of this licence, visit http://creativecommons.org/licenses/by/4.0/.

\section{REFERENCES}

1. Patton JS, Brain JD, Davies LA, Fiegel J, Gumbleton M, Kim K-J, et al. The particle has landed - characterizing the fate of inhaled pharmaceuticals. J Aerosol Med Pulmonary Drug Deliv. 2010;23:S-71-87.

2. Lu D, Lee SL, Lionberger RA, Choi S, Adams W, Caramenico $\mathrm{HN}$, et al. International guidelines for bioequivalence of locally acting orally inhaled drug products: similarities and differences. AAPS J Springer US. 2015;17:546-57.

3. Hastedt JE, Bäckman P, Clark AR, Doub W, Hickey A, Hochhaus G, et al. Scope and relevance of a pulmonary biopharmaceutical classification system AAPS/FDA/USP workshop March 16-17th, 2015 in Baltimore, MD. AAPS Open 2016 2:1. 2nd ed. Springer International Publishing; 2016;2:1.

4. Bäckman P, Adelmann H, Petersson G, Jones CB. Advances in inhaled technologies: understanding the therapeutic challenge, predicting clinical performance, and designing the optimal inhaled product. Clin Pharmacol Ther. 2014;95:509-20.

5. Olsson B, Bäckman P. Mouth-throat models for realistic in vitro testing - a proposal for debate. In: Dalby RN, Byron PR, Peart J, et al., editors. Proceedings of respiratory drug delivery 2014. River Grove, IL: DHI Publishing; 2014;1. p. 287-94.

6. Olsson B. The inhalation ad hoc advisory panel for the USP Performance Tests of inhalation dosage forms. 4Y:1-7.
7. Riley T, Christopher D, Arp J, Casazza A, Colombani A, Cooper A, et al. Challenges with developing in vitro dissolution tests for orally inhaled products (OIPs). AAPS PharmSciTech. 2012;13:978-89.

8. May S, Jensen B, Wolkenhauer M, Schneider M, Lehr C-M. Dissolution techniques for in vitro testing of dry powders for inhalation. Pharm Res. 2012;29:2157-66.

9. Shah VP, Tymes NW, Yamamoto LA, Skelly JP. In vitro dissolution profile of transdermal nitroglycerin patches using paddle method. Int J Pharm. 1986;32:243-50.

10. Shah VP, Tymes NW, Skelly JP. Comparative in vitro release profiles of marketed nitroglycerin patches by different dissolution methods. J Control Release. 1988;7:79-86.

11. Costa P, Lobo JMS. Modeling and comparison of dissolution profiles. Eur J Pharm Sci. 2001;13:123-33.

12. De Villiers MM, van der Watt JG. Dissolution rate a measurement of the Deaggregation of furosemide agglomerates during an interactive mixing process. Drug Dev Ind Pharm. 2008;16:1391-7.

13. Thorsson L, Edsbäcker S, Källén A, Claes-Göran L. Pharmacokinetics and systemic activity of fluticasone via Diskus and pMDI, and of budesonide via Turbuhaler. Clin Pharm. 2001;52:529-38.

14. Kuehl PJ, Barrett EG, Burke M, Chand R, DuBose D, Moeller $\mathrm{B}$, et al. Is systemic PK really an indicator of pulmonary deposition? A fluticasone propionate case study. In: Dalby R, Byron PR, Peart J, Suman JD, Farr SJ, Young PM, et al., editors. RDD Conference Paper. 2016 pp. 55-62.

15. Nyström $C$, Westerberg $M$. The use of ordered mixtures for improving the dissolution rate of low solubility compounds. J Pharm Pharmacol. 1986;38:161-5.

16. Kale K, Hapgood K, Stewart P. Drug agglomeration and dissolution-what is the influence of powder mixing? Eur J Pharm Biopharm. 2009;72:156-64.

17. De Villiers MM, van der Watt JG. The measurement of mixture homogeneity and dissolution to predict the degree of drug agglomerate breakdown achieved through powder mixing. Pharm Res. 1994;11:1557-61.

18. Allahham A, Stewart PJ. Enhancement of the dissolution of indomethacin in interactive mixtures using added fine lactose. Eur J Pharm Biopharm. 2007;67:732-42.

19. Allahham A, Maswadeh HM. Study of dissolution kinetics for poorly water-soluble drugs from ternary interactive mixtures in comparison with commercially available capsules. J Pharm Innov. 2014;9:106-14.

20. GlaxoSmithKline: Breo ${ }^{\mathrm{TM}}$ Ellipta ${ }^{\mathrm{TM}}$ briefing document for the pulmonary-Allergy Drug Advisory committee (NDA 204275); March-April 2013 [cited 2019 Oct 03]. Available from: http:// wayback.archive-it.org/7993/20170114022021/http:// www.fda.gov/downloads/AdvisoryCommittees/ Committees MeetingMaterials/Drugs/PulmonaryAllergyDrugsAdvisoryCommittee/UCM347931.pdf.

21. Sahasranaman S. Pharmacokinetic and pharmacodynamic evaluation of mometasone furoate [Doctoral dissertation]. [Gainesville, FL]: University of Florida; 2004.

22. Grasmeijer F, Hagedoorn P, Frijlink H, de Boer A. Drug content effects on the dispersion performance of adhesive mixtures for inhalation. PLoS One. 2013;8:1-12.

Publisher's Note Springer Nature remains neutral with regard to jurisdictional claims in published maps and institutional affiliations. 